\title{
Long-term prognosis after extracorporeal life support in refractory cardiogenic shock: results from a real-world cohort
}

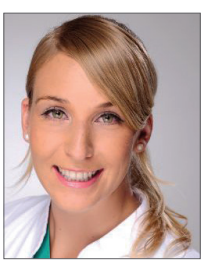

\author{
Suzanne de Waha ${ }^{1,2}$, MD; Georg Fuernau ${ }^{1,2}$, MD; Steffen Desch ${ }^{1,2}$, MD; Ingo Eitel ${ }^{1,2}$, MD; \\ Ariane Wiedau ${ }^{3}$, BSc; Philipp Lurz ${ }^{3}$, MD, PhD; Gerhard Schuler ${ }^{3}$, MD; Holger Thiele ${ }^{1,2}$, MD
}

1. University Heart Centre Lübeck, University Hospital Schleswig-Holstein, Medical Clinic II, Lübeck, Germany; 2. German Centre for Cardiovascular Research (DZHK), partner site Hamburg/Kiel/Lübeck, Lübeck, Germany; 3. University of Leipzig, Heart Center, Department of Internal Medicine - Cardiology, Leipzig, Germany

G. Schuler and H. Thiele share senior authorship.

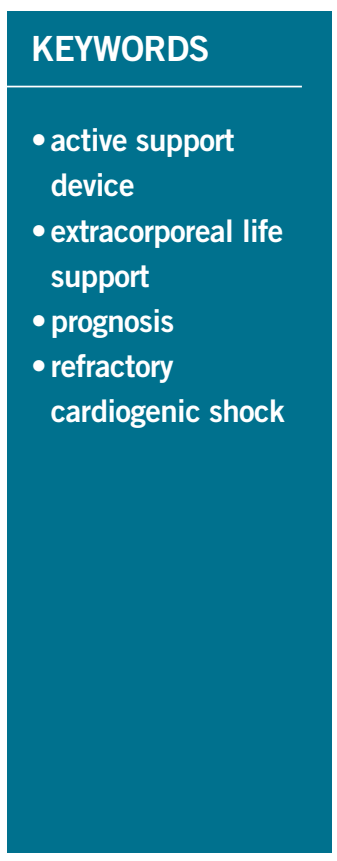

\begin{abstract}
Aims: The current study presents data from a real-world cohort of patients with refractory cardiogenic shock (CS) undergoing extracorporeal life support (ECLS) with the aims of reporting clinical experience, objectifying complications as well as survival, and identifying predictors of mortality.
\end{abstract}

Methods and results: Eighty-three patients with refractory CS underwent percutaneous ECLS implantation performed by interventional cardiologists. Follow-up was performed at hospital discharge as well as at 18 months (IQR 15-36). Good clinical outcome was defined as survival with a Cerebral Performance Category (CPC) of 1-2. Median age was 61 years (IQR 50-72) and cardiopulmonary resuscitation prior to ECLS implantation was performed in 46 patients $(55.4 \%)$. Aetiologies of CS were acute myocardial infarction $(63.9 \%)$, acute deterioration of ischaemic cardiomyopathy $(6.0 \%)$ or non-ischaemic acute heart failure $(16.9 \%)$, valvular heart disease (9.6\%), and interventional complications (3.6\%). Although initial ECLS weaning was successful in 47 patients $(56.6 \%)$, in-hospital mortality was $68.7 \%$. Of all 83 patients initially undergoing ECLS implantation, only 15 patients (18.1\%) were alive at follow-up, $13(15.7 \%)$ with a CPC of 1-2. Age was identified as an independent predictor of mortality $(\mathrm{p}=0.04)$.

Conclusions: Despite ECLS support, the long-term prognosis of patients with CS refractory to standard treatment remains poor.

*Corresponding author: University Heart Centre Lübeck, Medical Clinic II (Cardiology/Angiology/Intensive Care Medicine), University Hospital Schleswig-Holstein, Ratzeburger Allee 160, 23538 Lübeck, Germany.E-mail: s-dw@gmx.net 


\section{Abbreviations}

CPC Cerebral Performance Category

CS cardiogenic shock

ECLS extracorporeal life support

IQR interquartile range

PCI percutaneous coronary intervention

SAPS II Simplified Acute Physiology Score II

STEMI ST-elevation myocardial infarction

\section{Introduction}

Mortality due to cardiogenic shock (CS) remains high despite advanced treatment strategies ${ }^{1-3}$. In the setting of refractory CS, implantation of active assist devices may be the only option to achieve haemodynamic stability. As a consequence, current guidelines recommend that active support devices such as extracorporeal life support (ECLS) may be considered in selected patients ${ }^{4-6}$.

The concept of ECLS was first described in the 1970s 7 . Despite major advances in technology since it was first developed, ECLS remains invasive, resource intensive, and can be associated with serious complications ${ }^{8-12}$. These include life-threatening episodes of haemorrhage, thromboembolic events, infections, limb ischaemia or secondary consequences of prolonged immobilisation. The potential life-saving benefits of ECLS must therefore be weighed against its inherent risks. Data on prognosis in patients treated with ECLS are scarce and limited by small sample sizes as well as a relatively short duration of follow-up ${ }^{13-16}$. Further, as ECLS implantation has traditionally been performed by cardiothoracic surgeons, the majority of data derive from cohorts of patients with postoperative CS which is a different entity from CS in the absence of prior surgery ${ }^{17-19}$. Although evidence is lacking, ECLS use with percutaneous insertion in patients with refractory CS has risen considerably in recent years ${ }^{20,21}$.

The current analysis presents data from a large real-world cohort of patients with refractory CS undergoing ECLS with the aim of reporting clinical experience, objectifying complications as well as survival, and identifying predictors of mortality.

Editorial, see page 1337

\section{Methods \\ PATIENTS}

Data of patients undergoing ECLS due to refractory CS at one tertiary care centre were prospectively entered into an electronic hospital registry. Additional data required for this single-centre analysis were retrospectively evaluated. Patients undergoing ECLS implantation due to non-cardiac causes or postoperative CS were excluded.

The diagnosis of CS was made on established criteria, including i) systolic blood pressure $<90 \mathrm{mmHg}$ for $>30$ minutes or vasopressors required to achieve a blood pressure $\geq 90 \mathrm{mmHg}$; ii) pulmonary congestion or elevated left ventricular filling pressures; iii) signs of impaired organ perfusion with at least one of the following criteria: a) altered mental status; b) cold, clammy skin; c) oliguria; d) increased serum lactate. Patients included in the current analysis underwent ECLS due to refractory CS defined as critical circulatory failure resulting in organ hypoperfusion unresponsive to conventional therapy with minimal chance of survival without ECLS. Thus, patients had an increasing demand of inotrope and vasopressor doses at increasing levels of serum lactate prior to ECLS implantation. The likelihood of death in the absence of ECLS was deemed to be extremely high. Possible outcomes had to be: i) ECLS weaning to recovery (bridge to recovery); ii) heart transplantation (bridge to transplantation); or iii) implantation of a permanent left ventricular assist device (bridge to bridge).

Contraindications for ECLS implantation were severe comorbidities such as uncontrollable haemorrhage, irreversible brain damage, severe trauma or known terminal malignancies. The decision regarding ECLS implantation was taken by a team of cardiologists trained in intensive care medicine and interventional cardiology.

Detailed sets of clinical and functional parameters including the Simplified Acute Physiology Score II (SAPS II) were repeatedly $\operatorname{assessed}^{22}$. Further, all patients underwent continuous control of routine laboratory parameters, including serum lactate. Left ventricular ejection fraction was assessed by transthoracic echocardiography. Details on patients previous medical diagnoses such as history of symptomatic heart failure, chronic renal insufficiency ( $\geq$ stage 3 ) or peripheral artery disease were based on the information provided by the treating physician or hospital charts in accordance with guideline definitions $\mathbf{s}^{4,23,24}$.

\section{PROCEDURE}

ECLS implantation was performed in the catheterisation laboratory by experienced interventional cardiologists. The procedure was carried out regardless of working hours or days of the week (24 hours/7 days). All patients underwent coronary angiography prior to or at the time of ECLS implantation. Additional procedures such as percutaneous coronary intervention (PCI) or balloon valvuloplasty were performed according to standard clinical practice and guideline recommendations. ECLS implantation was performed with the assistance of perfusionists. All patients underwent ECLS implantation via a percutaneous femoro-femoral arteriovenous approach. Percutaneous cannulation using an $\sim 18 \mathrm{Fr}$ arterial cannula and an $\sim 22 \mathrm{Fr}$ venous cannula was performed using the Seldinger technique. To allow distal limb perfusion an $\sim 6 \mathrm{Fr}$ antegrade percutaneously introduced sheath was obligatory. Unfractionated heparin (70 U/kg body weight) was administered and the pump blood flow was initially set at 3 to $4 \mathrm{~L} / \mathrm{min}$.

\section{INTENSIVE CARE TREATMENT}

All therapeutic measures such as fluid management, renal replacement therapy, use of antibiotics or administration of additional medication were performed according to standard clinical practice and guideline recommendations ${ }^{25}$. While on ECLS, patients underwent heparinisation with an activated clotting time of 160-180 sec. In case of mechanical ventilation, lung protective ventilation was maintained. Although weaning of inotropes and vasopressors was targeted, additional dobutamine, norepinephrine, or epinephrine 
was administered if necessary for the shortest possible duration at the lowest possible dose to achieve a mean arterial blood pressure $>60 \mathrm{mmHg}$. Transfusions of packed red blood cells, platelets or fresh frozen plasma were restricted to the presence of clinically relevant bleeding problems.

Physicians working at the intensive care unit were all specifically trained on the ECLS technique and management.

\section{OUTCOME DEFINITIONS}

The primary outcome was long-term mortality. Secondary outcomes included i) in-hospital mortality, and ii) long-term survival with good functional outcome. Good functional outcome was defined as a score of 1-2 based on the Cerebral Performance Category (CPC) scale. Clinical follow-up was conducted prospectively via a structured telephone questionnaire contacting the patient, the relatives or the treating physician. All events were verified by hospital charts, direct contact with the treating physician or contact with the local government registration. Data on the cause of death prior to discharge and occurrence of local and systemic complications were assessed using in-hospital documentation.

\section{STATISTICAL ANALYSIS}

Each categorical variable is expressed as number and percentage of patients. Continuous data are reported as medians with corresponding interquartile range (IQR). Two-group comparisons for survivors versus non-survivors were performed with chi-square tests for categorical variables, Student's t-tests for normally distributed continuous variables and Wilcoxon rank-sum tests for non-normally distributed continuous variables. For outcome analysis, Kaplan-Meier curves with log-rank comparison were computed. To identify predictors of long-term mortality, univariable and multivariable Cox regression analyses were performed. All variables with a p-value $<0.1$ in univariable analysis were entered into a stepwise multivariable model. All statistical tests were performed with SPSS software, Version 19.0 (IBM Corp., Armonk, NY, USA). All probability values were two-tailed with $\alpha<0.05$, and confidence intervals $(\mathrm{CI})$ were calculated to the $95^{\text {th }}$ percentile.

\section{Results}

\section{BASELINE CHARACTERISTICS}

From January 2008 until October 2012, 83 patients underwent ECLS implantation due to refractory CS. As displayed in Table 1, the median age was 61 years (IQR 50-72, range 23-84). At the day of ECLS implantation, the SAPS II score was 53 (IQR 43-61) at a maximum level of serum lactate of $6.7 \mathrm{mmol} / 1$ (2.5-11.1). Prior to the procedure, 46 patients $(55.4 \%)$ had to undergo cardiopulmonary resuscitation.

The most common aetiology of CS was acute myocardial infarction $(n=53,63.9 \%)$ with ST-elevation myocardial infarction (STEMI) in 42 patients $(50.6 \%)$ and non-ST-elevation myocardial infarction in 11 (13.3\%). Ventricular septal defect (VSD) was present in four patients $(4.8 \%)$ with STEMI. Acute deterioration of chronic ischaemic cardiomyopathy was the cause of
$\mathrm{CS}$ in five patients $(6.0 \%)$. In patients with non-ischaemic acute heart failure $(n=14,16.9 \%)$, two patients $(2.4 \%)$ had acute fulminant myocarditis confirmed by histology, and one patient (1.2\%) displayed the typical pattern of Takotsubo cardiomyopathy. Other diagnoses were hypertrophic obstructive cardiomyopathy, arrhythmogenic right ventricular dysplasia, as well as refractory ventricular tachycardia due to intoxication attempting suicide (yew tree) and prolonged hypothermia (each $n=1,1.2 \%$ ). Dilated cardiomyopathy was present in the remaining seven patients $(8.4 \%)$ with non-ischaemic acute heart failure. Valvular heart disease as the primary diagnosis was present in eight patients $(9.6 \%$; aortic stenosis: $n=5,6.0 \%$; aortic insufficiency: $\mathrm{n}=1,1.2 \%$; mitral stenosis: $\mathrm{n}=1,1.2 \%$; mitral regurgitation $\mathrm{n}=1$, $1.2 \%$ ). Procedural complications leading to ECLS implantation were associated with transfemoral aortic valve replacement in two patients $(2.4 \%)$ and PCI in one $(1.2 \%)$.

\section{PROCEDURE, TREATMENT, AND COMPLICATIONS}

In the majority of patients, ECLS implantation was performed within 24 hours after development of haemodynamic instability $(n=52$, $63.7 \%$ /range 1-8 days). The implantation was exclusively performed in the catheterisation laboratory and was successful in all patients. ECLS support lasted in median six days (IQR 4-8, range 1-54).

Revascularisation was performed in all patients with acute myocardial infarction, with the exception of one case with known VSD as a mechanical complication of STEMI. PCI was performed in the majority of cases $(n=49,92.5 \%)$, and three patients underwent coronary artery bypass grafting (3.8\%). An additional PCI under mechanical support was performed in eight patients $(12.7 \%)$. Of the 53 patients with acute myocardial infarction, 19 (35.9\%) were treated with an intra-aortic balloon pump prior to ECLS. These were removed at ECLS implantation, and no other mechanical support systems (e.g., Impella $\mathrm{CP}^{\circledR}$; Abiomed Europe, Aachen, Germany) were inserted. Balloon valvuloplasty was performed in five patients with aortic $(n=4)$ or mitral stenosis $(n=1)$ following ECLS implantation. A permanent left ventricular assist device was implanted in one patient $(1.2 \%)$ after ECLS explantation, and three patients underwent heart transplantation on mechanical support $(3.6 \%)$.

Overall, nine patients $(10.8 \%)$ were spontaneously breathing, whereas 74 patients $(89.2 \%)$ had to be mechanically ventilated. Prior to ECLS implantation, 13 patients $(15.7 \%)$ were on renal replacement therapy. During ECLS, only two patients $(2.4 \%)$ could be weaned from renal replacement therapy, whereas an additional 22 (overall $n=33,39.8 \%$ ) experienced severe renal failure despite mechanical support. Antibiotic therapy had to be initiated in the vast majority of patients $(n=73,88.0 \%)$ with a septic shock constellation in 13 patients $(15.7 \%)$. Access-site complications occurred in almost one third of patients $(31.3 \%$, bleeding: $n=11$, $13.3 \%$; ischaemia: $n=6,7.2 \%$; infection: $n=9,10.8 \%$ ). Clinically relevant signs of haemolysis were not observed. Despite a relatively strict transfusion regimen, the majority of patients $(n=67$, $80.7 \%$ ) required either erythrocyte concentrates (median seven 
Table 1. Baseline characteristics of the whole study cohort and according to survival at hospital discharge.

\begin{tabular}{|c|c|c|c|c|c|}
\hline & & All patients $(n=83)$ & Survivors $(n=26)$ & Non-survivors $(n=57)$ & $p$-value \\
\hline Age, years & & $61(50-72)$ & $52(45-64)$ & $67(53-76)$ & 0.005 \\
\hline Male gender, $\mathrm{n}(\%)$ & & $61 / 83(73.5)$ & $19 / 26(73.1)$ & $42 / 57(73.7)$ & 1.00 \\
\hline Body mass index, $\mathrm{kg} / \mathrm{m}$ & & 27 (24-29) & $26(24-29)$ & 27 (24-29) & 0.82 \\
\hline Cardiovascular risk & Arterial hypertension & 49/71 (69.0) & $13 / 23(56.5)$ & $36 / 48(75.0)$ & 0.10 \\
\hline tact & Hyperlipidaemia & $30 / 68(44.1)$ & $11 / 23(47.8)$ & $19 / 45(42.2)$ & 0.43 \\
\hline & Diabetes mellitus & $24 / 70(34.3)$ & $7 / 23(30.4)$ & $17 / 47(36.2)$ & 0.42 \\
\hline & Current smoking & $29 / 71(40.8)$ & $8 / 24(33.3)$ & $21 / 47(44.7)$ & 0.25 \\
\hline Pre-existing & Coronary artery disease & 19/71 (26.8) & $4 / 24(16.7)$ & 15/47 (31.9) & 0.14 \\
\hline & Prior $\mathrm{PCl}$ & $16 / 69(23.2)$ & $3 / 23(13.0)$ & $13 / 46(28.3)$ & 0.13 \\
\hline & Prior $\mathrm{CABG}$ & 9/70 (12.9) & $1 / 23(4.3)$ & $8 / 47(17.0)$ & 0.13 \\
\hline & Prior ICD/CRT & $6 / 69(8.7)$ & $0 / 23(0.0)$ & $6 / 46(13.0)$ & 0.08 \\
\hline & Known symptomatic heart failure & $14 / 68(20.6)$ & $2 / 23(8.7)$ & $12 / 45(26.7)$ & 0.07 \\
\hline & Peripheral artery disease & 9/68 (13.2) & $1 / 23(4.3)$ & $8 / 45(17.8)$ & 0.12 \\
\hline & Chronic renal insufficiency & $19 / 69(27.5)$ & $3 / 23(13.0)$ & $16 / 46(34.8)$ & 0.05 \\
\hline & Acute myocardial infarction & $53 / 83(63.9)$ & $17 / 26(65.3)$ & $36 / 57(63.1)$ & 0.52 \\
\hline $\begin{array}{l}\text { cardogenic shock, } \\
\text { n (\%) }\end{array}$ & Ischaemic CMP & $5 / 83(6.0)$ & $1 / 26(3.8)$ & $4 / 57(7.0)$ & 0.50 \\
\hline & Non-ischaemic CMP & $14 / 83(16.9)$ & $7 / 26(26.9)$ & 7/57 (12.3) & 0.09 \\
\hline & Valvular heart disease & $8 / 83(9.6)$ & $0 / 26(0.0)$ & $8 / 8(100.0)$ & 0.04 \\
\hline & Interventional complications & $3 / 83(3.6)$ & $1 / 26(3.8)$ & $2 / 57(3.5)$ & 0.68 \\
\hline Functional parameters & LV ejection fraction, \% & $25(15-41)$ & $20(10-28)$ & $34(15-45)$ & 0.05 \\
\hline & Maximum serum lactate, $\mathrm{mmol} / \mathrm{l}$ & $6.7(2.5-11.1)$ & $8.6(3.7-10.6)$ & $5.9(2.4-12.2)$ & 0.83 \\
\hline & SAPS II score & $53(43-61)$ & $48(38-58)$ & $55(45-68)$ & 0.02 \\
\hline & ECLS at day 1 of shock, $n$ (\%) & $52 / 83(62.7)$ & $16 / 26(61.5)$ & $36 / 57(63.2)$ & 0.54 \\
\hline Cardiopulmonary & OHCA+in-house & $46 / 83(55.4)$ & $16 / 26(61.5)$ & $30 / 57$ (52.6) & 0.30 \\
\hline $\begin{array}{l}\text { resuscitatıon prior to } \\
\text { ECLS, n (\%) }\end{array}$ & $\mathrm{OHCA}$ & $13 / 83(15.7)$ & $7 / 26$ (26.9) & $6 / 57(10.5)$ & 0.06 \\
\hline & In-house & 33/83 (39.7) & 9/26 (35.6) & 24/57 (42.1) & 0.34 \\
\hline
\end{tabular}

CABG: coronary artery bypass grafting; CMP: cardiomyopathy; ECLS: extracorporeal life support; ICD/CRT: implantable cardiac defibrillator/cardiac resynchronisation therapy; LV: left ventricular; OHCA: out-of-hospital cardiac arrest; PCI: percutaneous coronary intervention; SAPS: Simplified Acute Physiology Score

packs/patient, IQR 2-13), thrombocyte replacement (median one pack/patient, IQR 0-2) or fresh frozen plasma (median two packs/ patient, IQR 2-4).

\section{IN-HOSPITAL OUTCOME}

ECLS could be weaned in more than half of the cohort $(n=47$, $56.6 \%$ ). Thus, 36 patients (43.4\%) could not be stabilised despite mechanical support (Figure 1). Following an initially successful ECLS explantation, an additional 21 patients died prior to hospital discharge (overall in-hospital mortality: 68.7\%, $n=57$ ). Causes of death were multi-organ failure due to prolonged or recurrent $\mathrm{CS}$ in the vast majority $(\mathrm{n}=41,71.9 \%)$ (Table 2$)$, whereas nine patients died due to septic shock (15.8\%), and two patients $(3.5 \%)$ experienced a major stroke. Two patients died due to anoxic brain injury $(3.5 \%)$. Finally, fatal haemorrhagic shock occurred in three patients $(5.3 \%$, haematothorax: $n=1,1.8 \%$; dislocation of the ECLS cannulas: $n=2,3.5 \%)$. After a median hospital stay of 20 days (IQR 13-37), 26 patients (31.3\%) could be discharged to undergo rehabilitation.
No patients undergoing ECLS due to CS in the setting of valvular heart disease survived. Further, all 14 patients above the age of 75 years died prior to hospital discharge (Figure 2A).

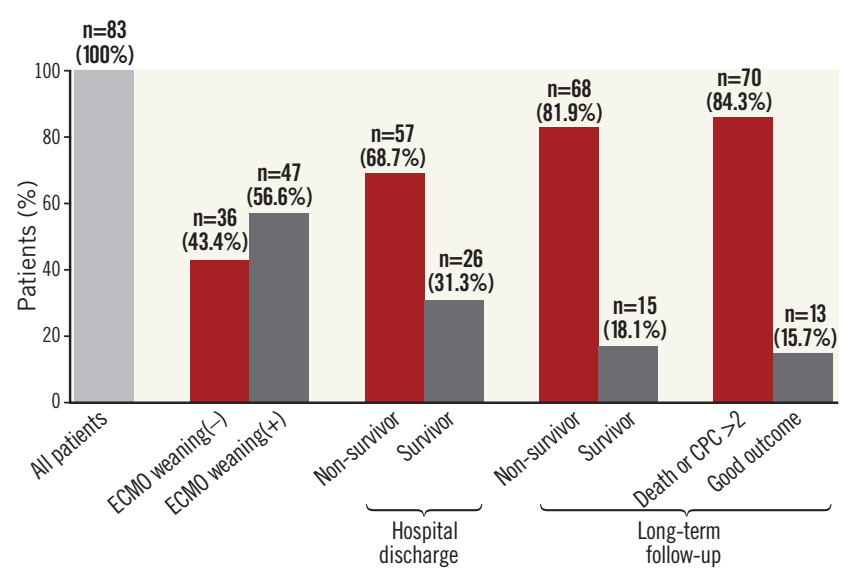

Figure 1. Overview of outcome. 

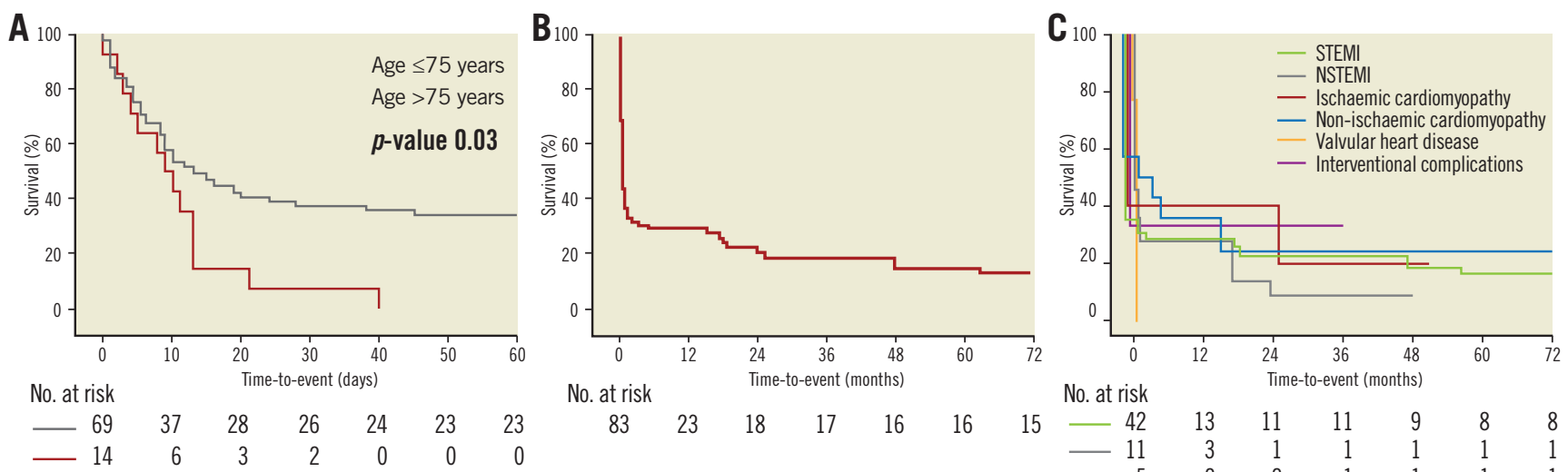

$\begin{array}{lllllll}83 & 23 & 18 & 17 & 16 & 16 & 15\end{array}$

No. at risk

$\begin{array}{rrrrrrr}-42 & 13 & 11 & 11 & 9 & 8 & 8 \\ -11 & 3 & 1 & 1 & 1 & 1 & 1 \\ -\quad 5 & 2 & 2 & 1 & 1 & 1 & 1 \\ -14 & 5 & 4 & 4 & 4 & 4 & 4 \\ -\quad 8 & 0 & 0 & 0 & 0 & 0 & 0 \\ 3 & 1 & 1 & 1 & 1 & 1 & 1\end{array}$

Figure 2. Survival following ECLS. A) Kaplan-Meier curve displaying short-term mortality according to age $>75$ versus $\leq 75$ years. B) Survival curve displaying long-term mortality. C) Survival curves displaying long-term mortality according to the aetiology of cardiogenic shock.

Table 2. Causes of in-hospital death.

\begin{tabular}{|l|c|}
\hline \multicolumn{1}{|c|}{ Cause of death, $\mathbf{n}(\%)$} & In-hospital death $(\mathbf{n = 5 7 )}$ \\
\hline Cardiogenic shock & $41(71.9)$ \\
\hline Septic shock & $9(15.8)$ \\
\hline Major stroke & $2(3.5)$ \\
\hline Anoxic brain injury & $2(3.5)$ \\
\hline Haemorrhagic shock & $3(5.3)$ \\
\hline
\end{tabular}

\section{LONG-TERM OUTCOME AND PREDICTORS OF ADVERSE CLINICAL OUTCOME}

Follow-up was completed in all patients alive at hospital discharge and was performed at 18 months (IQR 15-36). Of the 26 patients surviving the initial hospital stay, 11 died within the followup period (Figure 2B) and thus long-term mortality was $81.9 \%$ $(n=68)$. Of the 15 survivors, two had a CPC score of $>2$. Thus, of the 83 patients treated by ECLS, 13 survived with good functional outcome (15.7\%). Survival curves according to the aetiology of $\mathrm{CS}$ are shown in Figure 2C.

In multivariable Cox regression analysis, age, prior implantation of an internal cardiac defibrillator or cardiac resynchronisation therapy and known symptomatic heart failure were identified as independent predictors of long-term mortality (Table 3 ). The corresponding c-index of the model was 0.82 .

\section{SUB-ANALYSIS OF PATIENTS WITH ST-ELEVATION MYOCARDIAL INFARCTION}

STEMI patients were more often male and had a lower rate of prior ICD/CRT implantation as well as a lower prevalence of known symptomatic heart failure compared to patients who underwent ECLS for other indications (Table 4). Multivessel coronary artery disease was present in $40.5 \%(n=17 / 42)$. Of these, $94.1 \%(n=16 / 17)$ underwent additional PCI of non-culprit lesions $(n=16 / 42)$. The occurrence of bleeding did not differ between groups $(\mathrm{p}=0.25)$. The rate of ECLS weaning was similar $(54.8 \%$ versus $58.5 \%, \mathrm{p}=0.45)$. With respect to in-hospital mortality $(66.7 \%$ versus $70.7 \%, \mathrm{p}=0.44)$ and long-term mortality $(81.0 \%$ versus $82.9 \%, \mathrm{p}=0.53$ ), clinical outcome did not differ between STEMI patients and patients on ECLS due to other indications.

\section{Discussion}

The main findings of the current study are that i) prognosis of patients in refractory CS remains poor despite ECLS, ii) the rate of local and systemic complications under ECLS is high, and iii) ECLS is a therapeutic option in this otherwise futile situation, especially in younger patients.

Despite modern treatment strategies such as early revascularisation and optimal intensive care management, the mortality due to CS still approaches rates up to $50 \%{ }^{1-3}$. Medical therapy consists primarily of volume management as well as inotropic agents and vasopressors enhancing cardiac output and vascular tone. The haemodynamic benefits are counterbalanced by adverse effects such as increased myocardial oxygen demand, arrhythmogenicity, and compromise of tissue microcirculation which may translate into an increased mortality risk ${ }^{26,27}$. Mechanical circulatory support systems are an alternative to increase systemic blood flow avoiding the possible cardiotoxicity and long-term morbidity of medical therapy ${ }^{8-10}$. Intra-aortic balloon counterpulsation as the most widely used mechanical support system failed to show haemodynamic and clinical benefit in patients with infarct-related CS when tested in a randomised fashion ${ }^{2,28}$. ECLS provides a more potent haemodynamic support (ECLS: $>4.5 \mathrm{l} / \mathrm{min}$; intra-aortic balloon counterpulsation: $0.5-1.0 \mathrm{l} / \mathrm{min}$ ). This theoretically creates the opportunity to reduce the high mortality rates currently associated with conventionally managed CS. However, especially in patients without prior cardiac surgery, data on the safety and efficacy of ECLS in refractory CS are scarce, led to inconsistent results, and are limited due to small sample sizes as well as relatively short follow-up duration ${ }^{13-16}$. 
Table 3. Univariable and multivariable Cox regression analysis for long-term mortality.

\begin{tabular}{|c|c|c|c|c|c|}
\hline & & $\begin{array}{l}\text { Univariable HR } \\
\text { (95\% CI) }\end{array}$ & $p$-value & $\begin{array}{c}\text { Multivariable HR } \\
\text { (95\% Cl) }\end{array}$ & $p$-value \\
\hline \multicolumn{2}{|l|}{ Age, per 10 years } & $1.26(1.03-1.54)$ & 0.03 & $1.50(1.03-2.19)$ & 0.03 \\
\hline \multicolumn{2}{|l|}{ Male gender } & $1.05(0.56-1.97)$ & 0.87 & & \\
\hline \multicolumn{2}{|l|}{ Body mass index, $\mathrm{kg} / \mathrm{m}^{2}$} & $1.00(0.95-1.07)$ & 0.85 & & \\
\hline \multirow{4}{*}{$\begin{array}{l}\text { Cardiovascular risk } \\
\text { factors }\end{array}$} & Arterial hypertension & $1.35(0.70-2.61)$ & 0.38 & & \\
\hline & Hyperlipidaemia & $0.88(0.49-1.61)$ & 0.69 & & \\
\hline & Diabetes mellitus & $0.94(0.51-1.73)$ & 0.84 & & \\
\hline & Current smoking & $1.36(0.76-2.44)$ & 0.30 & & \\
\hline \multirow{7}{*}{$\begin{array}{l}\text { Pre-existing } \\
\text { comorbidities }\end{array}$} & Coronary artery disease & $1.23(0.69-2.34)$ & 0.45 & & \\
\hline & Prior PCl & $1.24(0.65-2.34)$ & 0.51 & & \\
\hline & Prior CABG & $1.44(0.67-3.12)$ & 0.35 & & \\
\hline & Prior ICD/CRT & $3.92(1.60-9.60)$ & 0.003 & $10.32(1.26-84.15)$ & 0.03 \\
\hline & Known symptomatic heart failure & $2.04(1.02-4.06)$ & 0.04 & $2.88(0.95-8.70)$ & 0.06 \\
\hline & Peripheral artery disease & $1.57(0.75-3.31)$ & 0.24 & & \\
\hline & Chronic renal insufficiency & $1.60(0.87-2.95)$ & 0.13 & & \\
\hline \multirow{5}{*}{$\begin{array}{l}\text { Aetiology of } \\
\text { cardiogenic shock }\end{array}$} & Acute myocardial infarction vs. other & $1.05(0.60-1.84)$ & 0.86 & & \\
\hline & Ischaemic CMP vs. other & $0.94(0.29-3.02)$ & 0.92 & & \\
\hline & Non-ischaemic CMP vs. other & $0.51(0.22-1.19)$ & 0.12 & & \\
\hline & Valvular heart disease vs. other & $2.55(1.19-5.50)$ & 0.02 & - & - \\
\hline & Interventional complications vs. other & $0.87(0.21-3.58)$ & 0.85 & & \\
\hline \multirow{4}{*}{$\begin{array}{l}\text { Functional parameters } \\
\text { at day of ECLS } \\
\text { implantation }\end{array}$} & LV ejection fraction, per $10 \%$ & $1.01(0.99-1.03)$ & 0.08 & - & - \\
\hline & Maximum serum lactate, $\mathrm{mmol} / \mathrm{l}$ & $1.00(0.93-1.06)$ & 0.86 & & \\
\hline & SAPS II score & $1.03(1.01-1.06)$ & 0.02 & - & - \\
\hline & ECLS at day 1 of shock & $0.83(0.51-1.37)$ & 0.47 & & \\
\hline \multirow{3}{*}{$\begin{array}{l}\text { Cardiopulmonary } \\
\text { resuscitation prior to } \\
\text { ECLS }\end{array}$} & OHCA+in-house & $1.04(0.60-1.78)$ & 0.90 & & \\
\hline & $\mathrm{OHCA}$ & $0.59(0.25-1.38)$ & 0.22 & & \\
\hline & In-house & $1.36(0.79-2.33)$ & 0.27 & & \\
\hline
\end{tabular}

A previous retrospective analysis by Sheu et al reporting data on 30-day survival in 46 patients with STEMI in profound shock demonstrated a mortality of $39.1 \%{ }^{13}$. The rate of peripheral complications associated with ECLS was $26.1 \%$, and in $87.0 \%$ of patients antibiotic treatment due to sepsis had to be initiated. Combes et al reported on 55 patients with acute myocardial infarction, dilated cardiomyopathy, and fulminant myocarditis $^{14}$. Mortality was $76.4 \%$ at a median follow-up of 11 months. Severe complications such as major bleeding, arterial ischaemia or wound infection occurred in $56.8 \%$. Almost one fifth of the patients $(18.5 \%)$ could only be transiently stabilised and had to undergo permanent assist device implantation or heart transplantation. In the cohort reported by Belle et al, in-hospital mortality was $51.9 \%$ in 27 patients with CS and $95.8 \%$ in 24 patients with refractory cardiac arrest $\mathrm{t}^{15}$. Further, the rate of complications was again high (e.g., major bleeding: 39.2\%, limb ischaemia: 17.6\%, sepsis: $13.7 \%$ ). Finally, Beurtheret et al recently published results of the cardiac-RESCUE program analysing data of 87 patients $^{16}$.
In-hospital mortality was $63.1 \%$. Notably, no patient above the age of 62 years survived, and more than half of all patients $(60 \%)$ suffered one to five complications while on ECLS support, including major stroke in $12.6 \%$.

The differing mortality rates can most likely be explained by the relatively small size of the reported cohorts with differing baseline characteristics. As demonstrated in the current analysis, age especially appears to be an independent predictor of inhospital as well as long-term mortality. This is supported by the finding of the current analysis that all patients over the age of 75 years died prior to hospital discharge. Patients enrolled in the cardiac-RESCUE program were $\sim 15$ years younger than those of the current analysis (46 versus 61 years) ${ }^{16}$. However, as demonstrated in the SHOCK trial (mean age 66 years) and the IABPSHOCK II trial (median age 70 years), CS frequently occurs in the elderly, and a cohort with a mean age of 46 years as presented in the cardiac-RESCUE program does not entirely reflect real-world patients ${ }^{1-3}$. 
Table 4. Baseline characteristics of patients with ST-elevation myocardial infarction versus other indications.

\begin{tabular}{|c|c|c|c|c|}
\hline & & STEMI $(n=42)$ & Other $(n=41)$ & $p$-value \\
\hline \multicolumn{2}{|l|}{ Age, years } & $59(50-71)$ & $64(50-76)$ & 0.82 \\
\hline \multicolumn{2}{|l|}{ Male gender, n (\%) } & $36 / 42(85.7)$ & 25/41 (61.0) & 0.01 \\
\hline \multirow{4}{*}{$\begin{array}{l}\text { Cardiovascular risk } \\
\text { factors, } \mathrm{n}(\%)\end{array}$} & Arterial hypertension & $22 / 33(66.7)$ & $27 / 38(71.1)$ & 0.44 \\
\hline & Hyperlipidaemia & $16 / 31(51.6)$ & $14 / 37(37.8)$ & 0.19 \\
\hline & Diabetes mellitus & $13 / 33(39.4)$ & $11 / 37(29.7)$ & 0.28 \\
\hline & Current smoking & $17 / 33(51.5)$ & $12 / 38(31.6)$ & 0.07 \\
\hline \multirow{7}{*}{$\begin{array}{l}\text { Pre-existing comorbidities, } \\
\text { n (\%) }\end{array}$} & Coronary artery disease & 10/32 (31.3) & 9/39 (23.1) & 0.31 \\
\hline & Prior $\mathrm{PCl}$ & $8 / 30(26.7)$ & $8 / 39(20.5)$ & 0.38 \\
\hline & Prior CABG & 4/31 (12.9) & $5 / 39(12.8)$ & 0.63 \\
\hline & Prior ICD/CRT & $0 / 30(0.0)$ & 6/39 (15.4) & 0.03 \\
\hline & Known symptomatic heart failure & $2 / 31(6.5)$ & $12 / 37(32.4)$ & 0.008 \\
\hline & Peripheral artery disease & $2 / 30(6.7)$ & $7 / 38(17.1)$ & 0.14 \\
\hline & Chronic renal insufficiency & $5 / 30(16.7)$ & $14 / 39(35.9)$ & 0.07 \\
\hline \multirow{4}{*}{$\begin{array}{l}\text { Functional parameters } \\
\text { prior to ECLS }\end{array}$} & LV ejection fraction, \% & $24(15-35)$ & $27(15-50)$ & 0.21 \\
\hline & Maximum serum lactate, $\mathrm{mmol} / \mathrm{l}$ & $7.6(3.7-11.7)$ & $6.5(2.4-10.8)$ & 0.95 \\
\hline & SAPS II score & $51(45-61)$ & $55(40-65)$ & 0.97 \\
\hline & ECLS at day 1 of shock, $n(\%)$ & $23 / 42(54.8)$ & 29/41 (70.7) & 0.10 \\
\hline
\end{tabular}

CABG: coronary artery bypass grafting; ECLS: extracorporeal life support; ICD/CRT: implantable cardiac defibrillator/cardiac resynchronisation therapy; LV: left ventricular; PCI: percutaneous coronary intervention; SAPS: Simplified Acute Physiology Score; STEMI: ST-elevation myocardial infarction

Further, the question of optimal timing of mechanical support might have been of importance. In the current analysis, all patients were in deep refractory CS with a likelihood of death deemed to be high in the absence of ECLS. Thus, one could argue that some patients were in a futile clinical situation. A potential benefit of an early use at the onset of CS could be prevention of multi-organ dysfunction syndrome. The current analysis primarily included patients undergoing ECLS at day one of CS. Further, no association of ECLS timing with mortality could be observed. In addition, the consistently high rate of complications associated with ECLS does not support the concept of early insertion and a widespread use in all CS patients irrespective of the severity of CS. Although the support provided by ECLS appears appealing as it is higher than with other potentially less invasive devices such as the Impella CP or the HeartMate PHPтM (Thoratec Corp., Pleasanton, CA, USA, currently under investigation to obtain CE approval in Europe), it may also have negative impact on outcome $^{11}$. This is especially important, as approximately $60 \%$ of patients will survive without any active device, as shown in the IABP-SHOCK II trial ${ }^{2}$. Consequently, early use of mechanical support devices might lead to complications with subsequent adverse clinical outcome in patients who still had non-invasive therapeutic options. Devices with low complication rates may thus be favoured in the early stage of CS. In the current study, care was taken to minimise complications (e.g., antegrade sheath to allow limb perfusion $)^{29}$. However, factors such as prolonged immobilisation which may promote systemic infection or bleeding associated with the large cannula size or derangements in coagulation and platelet function by extracorporeal circulation can hardly be modified. Further, the primary use of devices other than ECLS is supported by the fact that ECLS, in contrast to axial flow or left atrial to femoral artery devices, does not lead to left ventricular unloading. Rather, ECLS increases the afterload of the left ventricle, potentially enhancing oxygen demand and impeding myocardial protection, which may influence organ recovery ${ }^{30,31}$. Nevertheless, ECLS holds some advantages over other devices due to its ability to support right ventricular, left ventricular, or biventricular failure at very high blood flow rates, as well as the potential to support patients with concomitant lung injury by its oxygenation properties. These facts emphasise the role of ECLS as a potential bail-out strategy after failure of less invasive devices.

\section{Limitations}

Some important limitations of the current analysis need to be mentioned. First, the data are observational, and thus prone to selection bias. Second, the sample size is still too small to draw definitive conclusions. Nevertheless, the current study analyses data from one of the largest cohorts of patients without prior surgery undergoing ECLS so far published. Further, more haemodynamic parameters (e.g., heart rate) or additive laboratory data (e.g., leukocyte count) could have been included in the analysis. However, these parameters are included in the SAPS II score and thus were indirectly analysed. Inclusion of the SAPS II score instead of the individual components was performed to ensure statistical robustness by reducing the number of analysable parameters with respect to our sample size. Finally, we cannot provide data on haemodynamic indices such as cardiac index or 
pulmonary capillary wedge pressure. In addition, venting mechanisms and LA decompression were not assessed. The impact of these parameters and treatment procedures on outcome warrants further analyses.

\section{Conclusion}

Despite ECLS, the mortality of patients with refractory CS remains high. Next to the futile clinical state, this might also be in part explained by the high rate of local and systemic complications. Nevertheless, ECLS is a therapeutic option in high-risk patients, especially at a younger age.

\section{Impact on daily practice}

The long-term prognosis of patients with CS refractory to standard treatment remains poor, despite ECLS support. The rate of local and systemic complications associated with this mechanical support system is high. Thus, prevention as well as treatment of complications needs to be a major focus in ECLS therapy. Nevertheless, especially in younger patients, ECLS may be a therapeutic option in this otherwise futile situation.

\section{Conflict of interest statement}

The authors have no conflicts of interest to declare.

\section{References}

1. Hochman JS, Sleeper LA, Webb JG, Sanborn TA, White HD, Talley JD, Buller CE, Jacobs AK, Slater JN, Col J, McKinlay SM, LeJemtel TH. Early revascularization in acute myocardial infarction complicated by cardiogenic shock. SHOCK Investigators. Should We Emergently Revascularize Occluded Coronaries for Cardiogenic Shock. N Engl J Med. 1999;341:625-34.

2. Thiele H, Zeymer U, Neumann FJ, Ferenc M, Olbrich HG, Hausleiter J, Richardt G, Hennersdorf M, Empen K, Fuernau G, Desch S, Eitel I, Hambrecht R, Fuhrmann J, Böhm M, Ebelt H, Schneider S, Schuler G, Werdan K; IABP-SHOCK II Trial Investigators. Intraaortic balloon support for myocardial infarction with cardiogenic shock. N Engl J Med. 2012;367:1287-96.

3. Thiele H, Zeymer U, Neumann FJ, Ferenc M, Olbrich HG, Hausleiter J, de Waha A, Richardt G, Hennersdorf M, Empen K, Fuernau G, Desch S, Eitel I, Hambrecht R, Lauer B, Böhm M, Ebelt H, Schneider S, Werdan K, Schuler G; Intraaortic Balloon Pump in cardiogenic shock II (IABP-SHOCK II) trial investigators. Intra-aortic balloon counterpulsation in acute myocardial infarction complicated by cardiogenic shock (IABP-SHOCK II): final 12 month results of a randomised, open-label trial. Lancet. 2013;382:1638-45.

4. McMurray JJ, Adamopoulos S, Anker SD, Auricchio A, Böhm M, Dickstein K, Falk V, Filippatos G, Fonseca C, GomezSanchez MA, Jaarsma T, Køber L, Lip GY, Maggioni AP, Parkhomenko A, Pieske BM, Popescu BA, Rønnevik PK, Rutten FH, Schwitter J, Seferovic P, Stepinska J, Trindade PT, Voors AA, Zannad F, Zeiher A; ESC Committee for Practice
Guidelines. ESC Guidelines for the diagnosis and treatment of acute and chronic heart failure 2012: The Task Force for the Diagnosis and Treatment of Acute and Chronic Heart Failure 2012 of the European Society of Cardiology. Developed in collaboration with the Heart Failure Association (HFA) of the ESC. Eur Heart J. 2012;33:1787-847.

5. Authors/Task Force members, Windecker S, Kolh $\mathrm{P}$, Alfonso F, Collet JP, Cremer J, Falk V, Filippatos G, Hamm C, Head SJ, Jüni P, Kappetein AP, Kastrati A, Knuuti J, Landmesser U, Laufer G, Neumann FJ, Richter DJ, Schauerte P, Sousa Uva M, Stefanini GG, Taggart DP, Torracca L, Valgimigli M, Wijns W, Witkowski A. 2014 ESC/EACTS Guidelines on myocardial revascularization: The Task Force on Myocardial Revascularization of the European Society of Cardiology (ESC) and the European Association for Cardio-Thoracic Surgery (EACTS)Developed with the special contribution of the European Association of Percutaneous Cardiovascular Interventions (EAPCI). Eur Heart J. 2014;35: 2541-619.

6. Rihal CS, Naidu SS, Givertz MM, Szeto WY, Burke JA, Kapur NK, Kern M, Garratt KN, Goldstein JA, Dimas V, Tu T; Society for Cardiovascular Angiography and Interventions (SCAI); Heart Failure Society of America (HFSA); Society of Thoracic Surgeons (STS); American Heart Association (AHA), and American College of Cardiology (ACC). 2015 SCAI/ACC/HFSA/STS Clinical Expert Consensus Statement on the Use of Percutaneous Mechanical Circulatory Support Devices in Cardiovascular Care: Endorsed by the American Heart Assocation, the Cardiological Society of India, and Sociedad Latino Americana de Cardiologia Intervencion; Affirmation of Value by the Canadian Association of Interventional Cardiology-Association Canadienne de Cardiologie d'intervention. J Am Coll Cardiol. 2015;65:e7-e26.

7. Zapol WM, Snider MT, Hill JD, Fallat RJ, Bartlett RH, Edmunds LH, Morris AH, Peirce EC 2nd, Thomas AN, Proctor HJ, Drinker PA, Pratt PC, Bagniewski A, Miller RG Jr. Extracorporeal membrane oxygenation in severe acute respiratory failure. A randomized prospective study. JAMA. 1979;242:2193-6.

8. Abrams D, Combes A, Brodie D. Extracorporeal membrane oxygenation in cardiopulmonary disease in adults. $\mathrm{J} \mathrm{Am} \mathrm{Coll}$ Cardiol. 2014;63:2769-78.

9. Ouweneel DM, Henriques JP. Percutaneous cardiac support devices for cardiogenic shock: current indications and recommendations. Heart. 2012;98:1246-54.

10. Werdan K, Gielen S, Ebelt H, Hochman JS. Mechanical circulatory support in cardiogenic shock. Eur Heart J. 2014;35:156-67.

11. Thiele H, Ohman EM, Desch S, Eitel I, de Waha S. Management of cardiogenic shock. Eur Heart J. 2015;36:1223-30.

12. Lee JM, Park J, Kang J, Jeon KH, Jung JH, Lee SE, Han JK, Kim HL, Yang HM, Park KW, Kang HJ, Koo BK, Kim SH, Kim HS. The efficacy and safety of mechanical hemodynamic support in patients undergoing high-risk percutaneous coronary intervention with or without cardiogenic shock: Bayesian approach network meta-analysis of 13 randomized controlled trials. Int J Cardiol. 2015;184:36-46. 
13. Sheu JJ, Tsai TH, Lee FY, Fang HY, Sun CK, Leu S, Yang CH, Chen SM, Hang CL, Hsieh YK, Chen CJ, Wu CJ, Yip HK. Early extracorporeal membrane oxygenator-assisted primary percutaneous coronary intervention improved 30-day clinical outcomes in patients with ST-segment elevation myocardial infarction complicated with profound cardiogenic shock. Crit Care Med. 2010;38:1810-7.

14. Combes A, Leprince P, Luyt CE, Bonnet N, Trouillet JL, Léger P, Pavie A, Chastre J. Outcomes and long-term quality-of-life of patients supported by extracorporeal membrane oxygenation for refractory cardiogenic shock. Crit Care Med. 2008;36:1404-11.

15. Belle L, Mangin L, Bonnet H, Fol S, Santré C, Delavenat L, Savary D, Bougon D, Vialle E, Dompnier A, Desjoyaux E, Blin D. Emergency extracorporeal membrane oxygenation in a hospital without on-site cardiac surgical facilities. EuroIntervention. 2012;8:375-82.

16. Beurtheret S, Mordant P, Paoletti X, Marijon E, Celermajer DS, Léger P, Pavie A, Combes A, Leprince P. Emergency circulatory support in refractory cardiogenic shock patients in remote institutions: a pilot study (the cardiac-RESCUE program). Eur Heart J. 2013;34:112-20.

17. Rastan AJ, Dege A, Mohr M, Doll N, Falk V, Walther T, Mohr FW. Early and late outcomes of 517 consecutive adult patients treated with extracorporeal membrane oxygenation for refractory postcardiotomy cardiogenic shock. J Thorac Cardiovasc Surg. 2010;139:302-11, 311.e1.

18. Smedira NG, Moazami N, Golding CM, McCarthy PM, Apperson-Hansen C, Blackstone EH, Cosgrove DM 3rd. Clinical experience with 202 adults receiving extracorporeal membrane oxygenation for cardiac failure: survival at five years. $J$ Thorac Cardiovasc Surg. 2001;122:92-102.

19. Schmidt M, Burrell A, Roberts L, Bailey M, Sheldrake J, Rycus PT, Hodgson C, Scheinkestel C, Cooper DJ, Thiagarajan RR, Brodie D, Pellegrino V, Pilcher D. Predicting survival after ECMO for refractory cardiogenic shock: the survival after veno-arterialECMO (SAVE)-score. Eur Heart J. 2015;36:2246-56.

20. Paden ML, Conrad SA, Rycus PT, Thiagarajan RR; ELSO Registry. Extracorporeal Life Support Organization Registry Report 2012. ASAIO J. 2013;59:202-10.

21. Sauer CM, Yuh DD, Bonde P. Extracorporeal membrane oxygenation use has increased by $433 \%$ in adults in the United States from 2006 to 2011. ASAIO J. 2015;61:31-6.

22. Le Gall JR, Lemeshow S, Saulnier F. A new Simplified Acute Physiology Score (SAPS II) based on a European/North American multicenter study. JAMA. 1993;270:2957-63.

23. European Stroke Organisation, Tendera M, Aboyans V, Bartelink ML, Baumgartner I, Clément D, Collet JP, Cremonesi A, De Carlo M, Erbel R, Fowkes FG, Heras M, Kownator S, Minar E, Ostergren J, Poldermans D, Riambau V, Roffi M, Röther J, Sievert H, van Sambeek M, Zeller T; ESC Committee for Practice
Guidelines. ESC Guidelines on the diagnosis and treatment of peripheral artery diseases: Document covering atherosclerotic disease of extracranial carotid and vertebral, mesenteric, renal, upper and lower extremity arteries: the Task Force on the Diagnosis and Treatment of Peripheral Artery Diseases of the European Society of Cardiology (ESC). Eur Heart J. 2011;32:2851-906.

24. Kidney Disease: Improving Global Outcomes (KDIGO) CKD-MBD Work Group. KDIGO clinical practice guideline for the diagnosis, evaluation, prevention, and treatment of Chronic Kidney Disease-Mineral and Bone Disorder (CKD-MBD). Kidney Int Suppl. 2009:S1-130.

25. Werdan K, Ruß M, Buerke M, Delle-Karth G, Geppert A, Schöndube FA; German Cardiac Society; German Society of Intensive Care and Emergency Medicine; German Society for Thoracic and Cardiovascular Surgery; (Austrian Society of Internal and General Intensive Care Medicine; German Interdisciplinary Association of Intensive Care and Emergency Medicine; Austrian Society of Cardiology; German Society of Anaesthesiology and Intensive Care Medicine; German Society of Preventive Medicine and Rehabilitation. Cardiogenic shock due to myocardial infarction: diagnosis, monitoring and treatment: a German-Austrian S3 Guideline. Dtsch Arztebl Int. 2012;109:343-51.

26. Overgaard CB, Dzavik V. Inotropes and vasopressors: review of physiology and clinical use in cardiovascular disease. Circulation. 2008; 118:1047-56.

27. Jung C, Fuernau G, de Waha S, Eitel I, Desch S, Schuler G, Figulla HR, Thiele H. Intraaortic balloon counterpulsation and microcirculation in cardiogenic shock complicating myocardial infarction: an IABP-SHOCK II substudy. Clin Res Cardiol. 2015;104:679-87.

28. Prondzinsky R, Unverzagt S, Russ M, Lemm H, Swyter M, Wegener N, Buerke U, Raaz U, Ebelt H, Schlitt A, Heinroth K, Haerting J, Werdan K, Buerke M. Hemodynamic effects of intraaortic balloon counterpulsation in patients with acute myocardial infarction complicated by cardiogenic shock: the prospective, randomized IABP shock trial. Shock. 2012;37:378-84.

29. Avalli L, Sangalli F, Migliari M, Maggioni E, Gallieri S, Segramora V, Camesasca V, Formica F, Paolini G, Pesenti A. Early vascular complications after percutaneous cannulation for Extracorporeal Membrane Oxygenation for cardiac assist. Minerva Anestesiol. 2015 Apr 24. [Epub ahead of print].

30. Burkhoff D, Naidu SS. The science behind percutaneous hemodynamic support: a review and comparison of support strategies. Catheter Cardiovasc Interv. 2012;80:816-29.

31. Kawashima D, Gojo S, Nishimura T, Itoda Y, Kitahori K, Motomura N, Morota T, Murakami A, Takamoto S, Kyo S, Ono M. Left ventricular mechanical support with Impella provides more ventricular unloading in heart failure than extracorporeal membrane oxygenation. ASAIO J. 2011;57:169-76. 